\title{
Comparison of adherence between fixed and unfixed topical combination glaucoma therapies using Japanese healthcare/ pharmacy claims database: a retrospective non-interventional cohort study
}

\author{
Chikako Shirai $^{1}$, Nobushige Matsuoka ${ }^{2}$ and Toru Nakazawa ${ }^{3 *}$ (i)
}

\begin{abstract}
Background: Adherence to chronic therapies is crucial to prevent the progression of disease, such as glaucoma. However, only a limited number of studies have investigated them using real-world data in Japan. This study aimed to evaluate Japanese patients' adherence to fixed- and unfixed-combination eye drops as a second-line therapy for glaucoma in real-world practice.

Methods: This retrospective, non-interventional cohort study utilized a commercially available Japanese healthcare database (MinaCare database). Medical/pharmacy claims data were collected from 2011 to 2016. The primary endpoint was adherence to medications, assessed by proportion of days covered (PDC) with medication during a 12-month post-index period. Meanwhile, the secondary endpoints included the persistence rate.

Results: A total of 738 patients were included in this study: 309 and 329 in the fixed-and unfixed-combination cohorts, respectively. Prostaglandin analog (PG)/B-blocker (BB) was most commonly claimed in 241/309 (78.0\%) patients in the fixed-combination cohort. In the unfixed-combination cohort, PG and BB were claimed in 130/329 (39.5\%) patients, whereas PG and a2-agonist were claimed in 87/329 (26.4\%) patients. Patients were more adherent to the fixed-combination than the unfixed-combinations (mean PDCs [SD], 79.1\% [32.1] vs. 62.2\% [38.0]; $P<0.0001$ ). The proportion of patients with good adherence (PDC $\geq 80 \%)$ was also higher in the fixed-combination cohort (69.6\%) than in the unfixed-combination cohort (48.6\%) $(P<0.0001)$. During the 12-month post-index period, the persistence rate was higher in the fixed-combination cohort than in the unfixed-combination cohort (47.6\% [95\% confidence intervals (Cl): 41.9-53.0] vs. 24.9\% [95\% Cl: 20.4-29.7], $P<0.0001$ ).
\end{abstract}

Conclusions: Japanese patients with glaucoma preferred the fixed-combination therapies over the unfixedcombination therapies. Hence, fixed-combination therapies would contribute to the improvement of adherence.

Keywords: Adherence, Persistence, Glaucoma, Fixed-combination eye drops, Claims database, Latanoprost

* Correspondence: ntoru@oph.med.tohoku.ac.jp

${ }^{3}$ Department of Ophthalmology, Tohoku University Graduate School of Medicine, 1-1 Seiryo-machi, Aoba-ku, Sendai, Miyagi 980-8574, Japan

Full list of author information is available at the end of the article

C C The Author(s). 2021 Open Access This article is licensed under a Creative Commons Attribution 4.0 International License, which permits use, sharing, adaptation, distribution and reproduction in any medium or format, as long as you give appropriate credit to the original author(s) and the source, provide a link to the Creative Commons licence, and indicate if changes were made. The images or other third party material in this article are included in the article's Creative Commons licence, unless indicated otherwise in a credit line to the material. If material is not included in the article's Creative Commons licence and your intended use is not permitted by statutory regulation or exceeds the permitted use, you will need to obtain permission directly from the copyright holder. To view a copy of this licence, visit http://creativecommons.org/licenses/by/4.0/. The Creative Commons Public Domain Dedication waiver (http://creativecommons.org/publicdomain/zero/1.0/) applies to the data made available in this article, unless otherwise stated in a credit line to the data. 


\section{Background}

Glaucoma is the most common causative disease of blindness in Japan [1]. One of the critical risk factors for glaucoma is the intraocular pressure (IOP) [2-5]. IOPlowering eye drops and surgeries, such as selective laser trabeculoplasty (SLT) and minimally invasive glaucoma surgery (MIGS), have been developed and used for treatment. Consequently, glaucoma has become manageable, provided that it is diagnosed early and the treatment is implemented in a timely manner to prevent the development and delay the progression of the disease $[6,7]$. Recently a randomized study, called the LiGHT study, compared the clinical effectiveness as well as costeffectiveness between the eye drops and the SLT groups and demonstrated that SLT is cost effective, suggesting that SLT should be offered as a first-line treatment for open-angle glaucoma and ocular hypertension [8]. However, IOP-lowering eye drops still remain a first-line treatment option in many countries including Japan.

The treatment for glaucoma is generally started with a monotherapy, such as prostaglandin analogs (PG) or $\beta$ blockers (BB). If the first monotherapy is ineffective or intolerable, switching to another monotherapy is preferred. Whenever a monotherapy does not reach the target IOP or the target must be lowered as the disease progresses, a concomitant therapy with a medication that has a different mechanism of action should be considered. If such treatment regimens are successful, patients can avoid laser intervention and surgery. However, adherence to the therapy should be crucially improved for a successful glaucoma treatment [9], considering that nonadherence to glaucoma therapies has been a serious concern [10, 11].

Risk factors for nonadherence to glaucoma therapies include patients' problems (financial concern, poor understanding of the disease, and frequent eye drop application), healthcare providers' issues (insufficient instruction/explanation and assessment of each patient's conditions), and the relationship between patients and physicians (lack of communication and trust) [12-14]. A previous study reported that a fixed-combination therapy improved the long-term adherence of patients with glaucoma compared with the unfixed therapy [15]. According to a nationwide survey performed in 2011-2012 in Japan using a questionnaire, good adherence to IOPlowering eye drops was observed in $72.4 \%$ of patients [16]. However, these risk factors and adherence rates were based on the data obtained from clinical studies under controlled conditions or an experimental setting. Therefore, patients' adherence to the therapies should be investigated, and the risk factors in ordinary clinical settings should be determined using real-world data.

In several previous studies, adherence to glaucoma therapies was evaluated using pharmacy claims data
[17-22]. Unfortunately, to our knowledge, no such study has been conducted in Japan. Therefore, this study aimed to compare patients' adherence between a fixedcombination therapy and an unfixed-combination therapy and to identify risk factors for nonadherence in Japanese patients with glaucoma by using a healthcare database.

\section{Methods}

\section{Study design}

This retrospective cohort study utilized a commercially available Japanese administrative healthcare database (MinaCare Co., Ltd., Tokyo, Japan) to investigate the adherence of patients to fixed-combination and unfixedcombination therapies for glaucoma treatment after switching from a monotherapy. The study consisted of a 12-month pre-index period, an index date (defined as a first prescription day of either when a single eye drop was first switched to a fixed-combination therapy [fixedcombination cohort] or when the second eye drop was added to a single eye drop initially [unfixed-combination cohort]), and a 12-month post-index period. Patients without claims for 12 months after the index date and those who claimed the third drug in addition to a fixedcombination therapy or in addition to an unfixedcombination therapy indicated withdrawal. Approval for this research by an ethical review committee and informed consent of each subject were not required because studies using only unlinkably anonymized data are outside the scope of "Ethical Guidelines for Medical and Health Research Involving Human Subjects" [23] set by the Japanese government.

\section{Data source and study cohort}

The MinaCare database includes anonymized data on both health checkup and medical/pharmacy claims of workers and their family members in a wide range of age groups below the age of 75 years [24, 25]. Maintained by MinaCare Co., Ltd., this database is updated periodically with newly available data obtained from the employment-based health insurance groups. It includes the data of 6.3 million uniquely identified individuals as of April 2017 and has recorded the information of 1.8 million patients from April 2016 to March 2017, covering $1.7 \%$ of the Japanese population under the age of 75 years [26]. Furthermore, it is generally consistent with two national databases and is useful as it has low selection bias and large sample size with wide age distribution; however, it only targets national-wide big corporations, such as manufacturing, food, information transportation, and energy industries, and does not include individuals in the primary industry (agriculture, fisheries, forestry, etc.) or those who are self-employed [24]. 
Patients were extracted from the database with the ICD10 diagnosis codes H401 (normal tension glaucoma, primary open-angle glaucoma, and open-angle glaucoma) and H409 (unspecified glaucoma) and with prescription claims for the eye drops to treat glaucoma between April 1, 2011 and March 31, 2016. In addition, we extracted the clinical laboratory data, such as anthropometric measurements, blood pressure, blood glucose levels, blood lipid levels, liver function test values, hematologic values, and urine test values, from the health checkup database. We included those who had received monotherapy for 1 year or longer without surgery including laser treatment and then switched to a fixed-combination therapy as second-line treatment (the fixed-combination cohort) or those who received an additional eye drop, such as timolol as an addition to latanoprost or vice versa, as second-line treatment (the unfixed-combination cohort). The first prescription date of the second-line therapy was defined as the index date. Patients without prescription of a fixed or unfixedcombination therapy, with history of surgery or laser surgery for glaucoma, or with pre-index monotherapy for $<12$ months were excluded.

\section{Study endpoints}

The primary endpoint was medication adherence, which was assessed by the proportion of days covered (PDC) with medication over the 12-month post-index period. The a priori definition of adherence cutpoint was $80 \%$. Meanwhile, the secondary endpoints were related to medication persistence, defined as the act of continuing the use of claimed eye drops, and included persistence rate and its duration, a distribution of patients according to the type of claimed eye drops at the index date and switching patterns of eye drops during the 12-month post-index period. In addition, the risk factors for PDC < $80 \%$ were analyzed.

\section{Assessments}

Subject background characteristics included sex, age, body weight, height, body mass index, smoking status/history, health examination results, comorbidity, residence region, the number of eye drop bottles consumed, and eye drop types. These characteristics were summarized in all patients and in each cohort. Moreover, residence regions were classified into eight regions from Hokkaido to Kyushu including Okinawa [27], two areas (East Japan vs. West Japan) [28], and city sizes (big cities including Tokyo and 20 ordinance-designated cities vs. the others) [29]. We also identified the PDC over 12 months after the index date in all patients and each cohort, the risk factors for $\mathrm{PDC}<80 \%$, and the persistence rate.
To address the possible variations in the dosage and prescribed period reported on a claim for glaucoma medication, we made adjustments based on the unit volume of the formulation. For example, if the dosage was "7.5" and the period was " 1 " in a claim, we converted them to " $2.5 \mathrm{~mL}$ (approved bottle) $\times 3$ bottles" prescribed for 3 months because one bottle $(2.5 \mathrm{~mL}$ for once-daily formulations or $5 \mathrm{~mL}$ twice-or-more-daily formulations) is enough to apply one eye for more than 30 days but is correspondent to 30 days dispensed. The general recommendation of the use-by period of opened eye drop bottles is generally 4 weeks in Japan. Accordingly, the patients were permitted a 30-day grace period to obtain the next prescription. In addition, if one prescription consists of $\geq 7$ bottles, the patient was considered receiving treatment of both eyes. Therefore, a PDC value was calculated using the following formula:

$\operatorname{PDC}(\%)=($ total prescription days during the $365-$ day assessment $/ 365$ days $) \times 100$

In this study, the PDC is calculated according to the period only prescribed with two-drug fixed-combination drops or two-drug unfixed-combination therapies, regardless of switching drug class [e.g., PG + BB to PG+ carbonic anhydrase inhibitor (CAI)].

Persistence refers to the act of continuing index therapy (i.e., a fixed-combination therapy or an unfixedcombination therapy). The definition of "persistence" is the duration in days from the index date (the first prescription date of the index therapy) to the last prescription date + prescription days or to the discontinuation date allowing a 30-day grace period. In the case of one drug addition to the combination of two drugs (e.g., $\mathrm{PG}+\mathrm{BB}$ to $\mathrm{PG}+\mathrm{BB}+\mathrm{AA}$ ), it was considered as "discontinued/withdrawn." Likewise, in a subset analysis using specific drug classes, no prescription record for more than 30 days or switched or changed prescriptions were treated as "discontinued." The cumulative discontinuation rate was analyzed based on the time to discontinuation and was estimated using the Kaplan-Meier method. Patients who continued the treatment for 12 months were treated as censored at 12 months. The persistence rate at the evaluated time point was calculated as follows:

Persistence rate $(\%)=100 \%$ - cumulative discontinuation rate

\section{Statistical analysis}

We presented summary statistics (mean and standard deviation [SD] or a number and a proportion of patients) for the patients' background characteristics and PDC. Using $t$-test, we compared the mean PDC values between two cohorts. Furthermore, proportions of patients with or without $\geq 80 \%$ PDC between two cohorts were 
compared using Pearson's $\chi^{2}$ tests. Bonferroni correction was used to adjust for multiplicity $(\mathrm{m}=9$, where $\mathrm{m}$ is the total number of statistical tests in this study). A $p$ value $=<0.00556(0.05 / 9)$ was considered statistically significant for comparisons between the groups. We also explored the risk factors for nonadherence to the medications ( $\mathrm{PDC}<80 \%$ ) by using a univariate logistic regression model. Subsequently, multivariate analyses were performed for those with $P<0.1$, followed by a stepwise (forward and backward) logistic regression model. The odds ratios (OR) and Wald 95\% confidence intervals (CIs) were presented. The subject persistence rates at 6 and 12 months with a pointwise $95 \%$ CI were estimated using the Kaplan-Meier method, and the differences between the two treatment cohorts were tested by log-rank test. All the statistical analyses were performed using the SAS version 9.4 (SAS Institute Inc., Cary, NC, USA).

\section{Results}

In total, 57,899 patients were diagnosed with glaucoma and prescribed with any IOP-lowering drug in the database, of whom 309 patients were in the fixedcombination cohort and 329 patients were in the unfixed-combination cohort (Fig. 1). The two cohorts had similar baseline demographic and clinical characteristics (Table 1). The mean age was $56-57$ years and clinical measurement values were within the normal ranges. Comorbidities reported in $>20 \%$ of patients were hypertension, hyperlipidemia, diabetes mellitus, and cancer. In both cohorts, over $80 \%$ of patients lived in East Japan (especially residents of Tokyo or large cities).

The eye drops claimed at the index date are summarized in Fig. 2. In the fixed-combination cohort, PG/BB (78.0\%) and CAI/BB (22.0\%) were used by drug class, and the most commonly used eye drop was latanoprost/ timolol (39.8\%) by generic name. In the unfixedcombination cohort, the top three most frequently administered drug combinations were $\mathrm{PG}+\mathrm{BB}$ (39.5\%), $\mathrm{PG}+\alpha 2$-agonist (AA) (26.4\%), and PG + CAI (14.3\%) by drug class; the most common drugs were latanoprost and brimonidine (12.2\%), followed by latanoprost and timolol (11.9\%) by generic name.

Common patterns of switching eye drops during the post-index period are shown in Fig. 3. In the fixedcombination cohort, out of 241 patients prescribed with PG/BB, 165 (68.5\%) continued the same drug class, and out of 68 patients prescribed with CAI/BB, 38 (55.9\%) continued the same drug class. Other major switching patterns were the addition of AA or CAI. In the unfixed cohort, the same drug class combination therapies were continued by only less than $50 \%$ of patients, regardless of the kind of combination.

The mean PDC over the 12-month post-index period was $70.4 \%$ in all the patients, $79.1 \%$ in the fixedcombination cohort, and $62.2 \%$ in the unfixedcombination cohort; hence, the PDC in the fixedcombination cohort was significantly higher than that in the unfixed-combination cohort $(P<0.0001)$ (Table 2). High adherence (PDC $\geq 80 \%$ ) was observed in $58.8 \%$ of all the patients, $69.6 \%$ in the fixed-combination cohort, and $48.6 \%$ in the unfixed-combination cohort; hence, it was significantly higher in the fixed-combination cohort than in the unfixed-combination cohort $(P<0.0001)$. As for the popular combination of latanoprost and timolol, the mean PDC was $82.9 \%$ in the fixed-combination cohort and $66.5 \%$ in the unfixed-combination cohort; hence, it was higher in the fixed-combination cohort $(P=0.0191)$ (Table 3), but it was not significant (NS). A

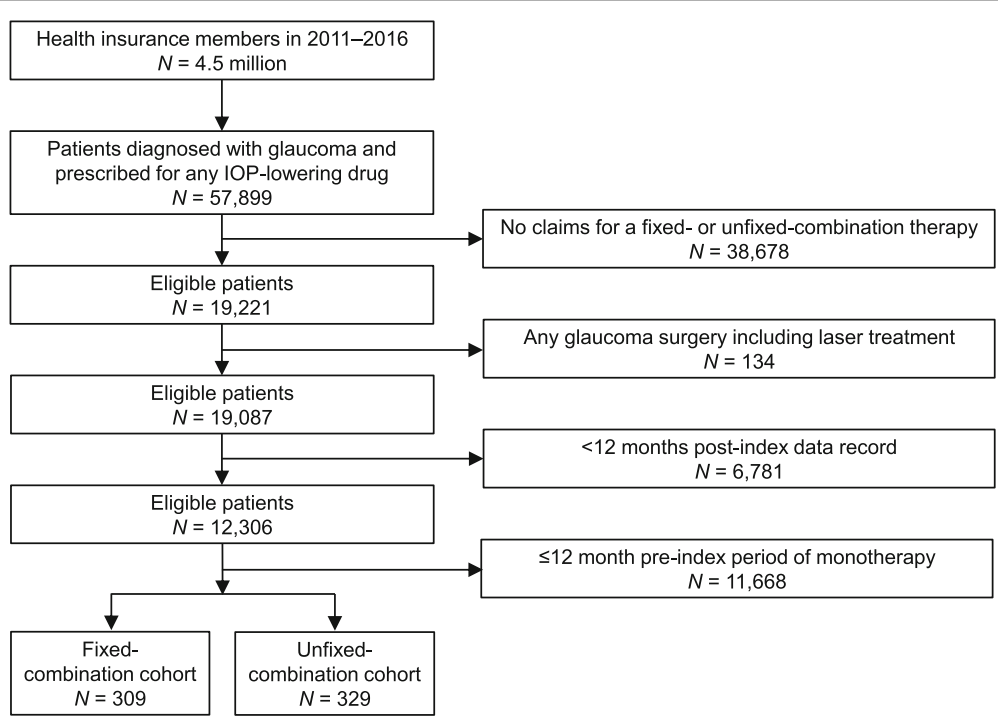

Fig. 1 Flowchart for data extraction. IOP, intraocular pressure 
Table 1 Baseline demographic and clinical characteristics of subjects

\begin{tabular}{|c|c|c|c|c|}
\hline \multirow[t]{2}{*}{ Variable } & \multicolumn{2}{|c|}{ Fixed combination $(N=309)$} & \multicolumn{2}{|c|}{ Unfixed combination $(N=329)$} \\
\hline & $\bar{n}$ & Percentage or mean $\pm S D$ & $\bar{n}$ & Percentage or mean $\pm S D$ \\
\hline Sex, male & 170 & 55.0 & 188 & 57.1 \\
\hline Age (years) & 309 & $56.5 \pm 10.2$ & 329 & $57.1 \pm 10.2$ \\
\hline Body weight (kg) & 210 & $61.8 \pm 12.5$ & 219 & $61.6 \pm 11.0$ \\
\hline Height (cm) & 218 & $163.9 \pm 9.2$ & 226 & $164.4 \pm 8.9$ \\
\hline Body mass index $\left(\mathrm{kg} / \mathrm{m}^{2}\right)$ & 210 & $22.9 \pm 3.5$ & 219 & $22.7 \pm 3.1$ \\
\hline \multicolumn{5}{|l|}{ Smoking } \\
\hline Yes & 33 & 10.7 & 32 & 9.7 \\
\hline No & 178 & 57.6 & 193 & 58.7 \\
\hline \multicolumn{5}{|l|}{ Medication for other indications } \\
\hline Yes & 63 & 20.4 & 74 & 22.5 \\
\hline No & 146 & 47.2 & 149 & 45.3 \\
\hline Fasting blood glucose (mg/dL) & 200 & $97.0 \pm 17.4$ & 213 & $97.8 \pm 15.4$ \\
\hline HbA1c (NGSP) (\%) & 205 & $5.6 \pm 0.6$ & 216 & $5.6 \pm 0.5$ \\
\hline \multicolumn{5}{|l|}{ Urine glucose } \\
\hline Negative $(-)$ & 208 & 67.3 & 221 & 67.2 \\
\hline Positive $(\geq \pm)$ & 4 & 1.3 & 2 & 0.6 \\
\hline \multicolumn{5}{|l|}{ Urine protein } \\
\hline Negative $(-)$ & 192 & 62.1 & 207 & 62.9 \\
\hline Positive $(\geq \pm)$ & 24 & 7.8 & 19 & 5.8 \\
\hline \multicolumn{5}{|l|}{ Antihypertensive drug } \\
\hline Yes & 46 & 14.9 & 52 & 15.8 \\
\hline No & 163 & 52.8 & 171 & 52.0 \\
\hline Systolic blood pressure (mm Hg) & 218 & $119.9 \pm 15.5$ & 226 & $120.3 \pm 16.2$ \\
\hline Diastolic blood pressure $(\mathrm{mm} \mathrm{Hg})$ & 218 & $74.5 \pm 11.3$ & 226 & $75.6 \pm 11.2$ \\
\hline Total cholesterol (mg/dL) & 64 & $207.3 \pm 32.0$ & 53 & $201.7 \pm 35.9$ \\
\hline Triglycerides (mg/dL) & 217 & $107.9 \pm 64.8$ & 226 & $101.3 \pm 66.6$ \\
\hline HDL cholesterol (mg/dL) & 217 & $64.6 \pm 16.7$ & 226 & $65.0 \pm 16.9$ \\
\hline LDL cholesterol (mg/dL) & 217 & $124.4 \pm 26.9$ & 226 & $126.2 \pm 31.2$ \\
\hline Aspartate transaminase $(\mathrm{U} / \mathrm{L})$ & 217 & $23.7 \pm 9.3$ & 226 & $23.0 \pm 8.8$ \\
\hline Alanine aminotransferase $(U / L)$ & 217 & $23.3 \pm 14.6$ & 226 & $23.5 \pm 13.6$ \\
\hline$\gamma-G T P(U / L)$ & 216 & $41.4 \pm 49.1$ & 226 & $37.6 \pm 41.6$ \\
\hline \multicolumn{5}{|l|}{ Common comorbidities } \\
\hline Hypertension & 92 & 29.8 & 110 & 33.4 \\
\hline Cancer & 90 & 29.1 & 114 & 34.7 \\
\hline Hyperlipidemia & 87 & 28.2 & 111 & 33.7 \\
\hline Diabetes mellitus & 85 & 27.5 & 97 & 29.5 \\
\hline Insomnia & 44 & 14.2 & 44 & 13.4 \\
\hline Liver disorder & 43 & 13.9 & 44 & 13.4 \\
\hline Asthma or COPD & 41 & 13.3 & 66 & 20.1 \\
\hline Gastrointestinal ulcer & 38 & 12.3 & 41 & 12.5 \\
\hline Atherosclerosis or PAOD & 31 & 10.0 & 38 & 11.6 \\
\hline Anemia & 30 & 9.7 & 33 & 10.0 \\
\hline Coronary artery disease & 26 & 8.4 & 33 & 10.0 \\
\hline
\end{tabular}


Table 1 Baseline demographic and clinical characteristics of subjects (Continued)

\begin{tabular}{|c|c|c|c|c|}
\hline \multirow[t]{2}{*}{ Variable } & \multicolumn{2}{|c|}{ Fixed combination $(N=309)$} & \multicolumn{2}{|c|}{ Unfixed combination $(N=329)$} \\
\hline & $\bar{n}$ & Percentage or mean $\pm S D$ & $n$ & Percentage or mean $\pm S D$ \\
\hline Heart failure & 22 & 7.1 & 35 & 10.6 \\
\hline \multicolumn{5}{|l|}{ Locations } \\
\hline \multicolumn{5}{|l|}{8 regions } \\
\hline Hokkaido & 7 & 2.3 & 3 & 0.9 \\
\hline Tohoku & 14 & 4.5 & 6 & 1.8 \\
\hline Kanto & 176 & 57.0 & 207 & 62.9 \\
\hline Chubu & 38 & 12.3 & 37 & 11.2 \\
\hline Kinki & 38 & 12.3 & 36 & 10.9 \\
\hline Chugoku & 10 & 3.2 & 9 & 2.7 \\
\hline Shikoku & 2 & 0.6 & 2 & 0.6 \\
\hline Kyushu & 24 & 7.8 & 29 & 8.8 \\
\hline \multicolumn{5}{|l|}{ Areas } \\
\hline East Japan & 210 & 68.0 & 220 & 66.9 \\
\hline West Japan & 99 & 32.0 & 109 & 33.1 \\
\hline \multicolumn{5}{|l|}{ City size } \\
\hline Tokyo and all GODMCs & 255 & 82.5 & 289 & 87.8 \\
\hline Other than GODMCs & 54 & 17.5 & 40 & 12.2 \\
\hline
\end{tabular}

HBA1c hemoglobin A1c, NGSP National Glycohemoglobin Standardization Program, HDL high-density lipoprotein, LDL low-density lipoprotein, COPD chronic obstructive pulmonary disease, $\gamma$-GTP $\gamma$-glutamyl transpeptidase, $P A O D$ peripheral arterial occlusive disease, GODMCS government ordinance-designed major cities

proportion of patients with $\mathrm{PDC} \geq 80 \%$ was $75.6 \%$ in the fixed-combination cohort and $53.8 \%$ in the unfixedcombination cohort, showing that it was higher in the fixed-combination cohort $(P=0.0095$, NS). Furthermore, when compared between the $\mathrm{PG} / \mathrm{BB}$ and $\mathrm{CAI} / \mathrm{BB}$ of the same fixed-combination cohort, PG/BB had an approximately $10 \%$ higher mean $\mathrm{PDC}$ value $(P=0.0438, \mathrm{NS})$ and an approximately $15 \%$ higher proportion of patients with good adherence $(P=0.0131$, NS) (Table 4 ).

Univariate analyses identified treatment (fixed-combination vs. unfixed-combination) and hemoglobin A1c (HbA1c) as potential risk factors for nonadherence $(P<$ 0.1) (Table 5). Conversely, variables, such as age, sex, body mass index, smoking habit, hospital locations, and
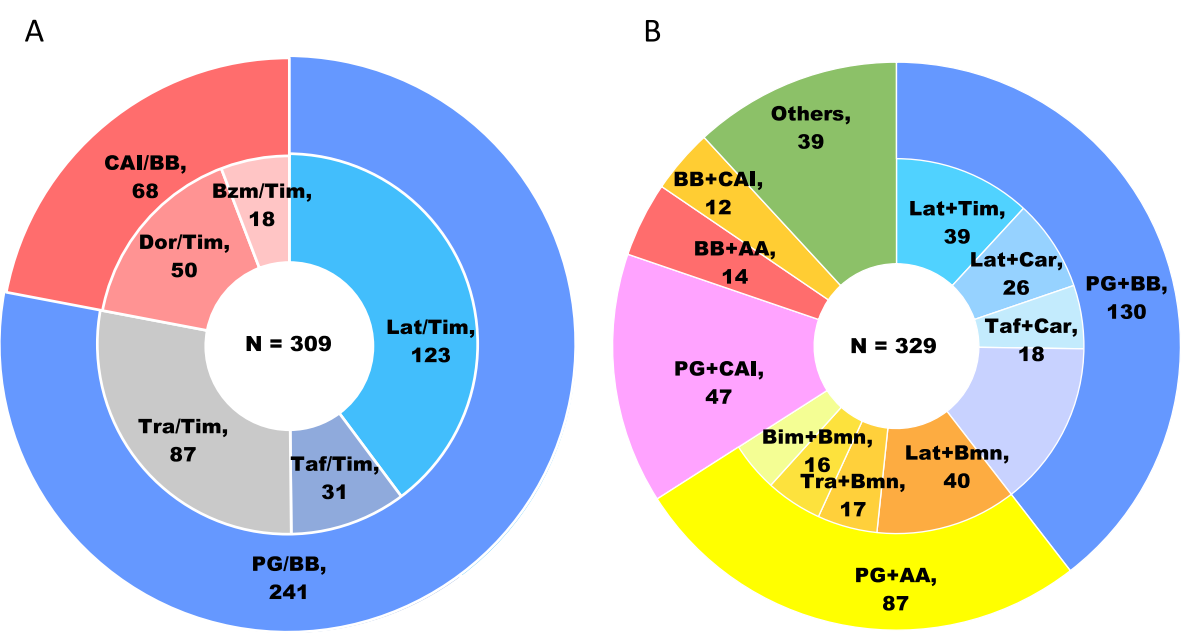

Fig. 2 Drug class distribution of prescribed eye drops on the index date in the fixed-combination (a) and unfixed-combination (b) cohorts. AA, a2-agonist; BB, $\beta$-blocker; Bim, bimatoprost; Bmn, brimonidine; Bzm, brinzolamide; CAl, carbonic anhydrase inhibitor; Car, carteolol; Dor, dorzolamide; Lat, latanoprost; PG, prostaglandin analog, Taf, tafluprost; Tim, timolol; Tra, travoprost 
A

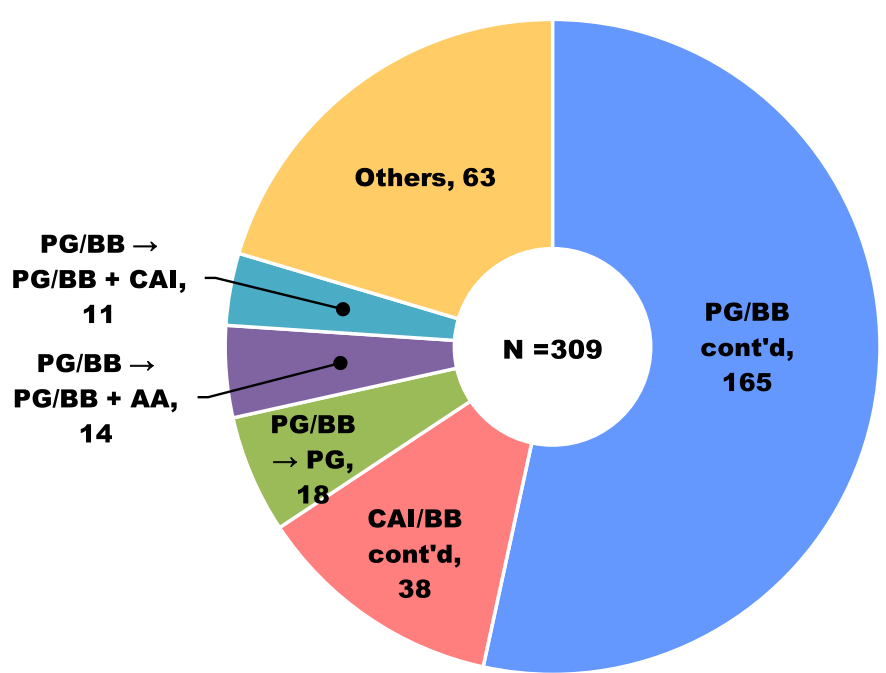

B

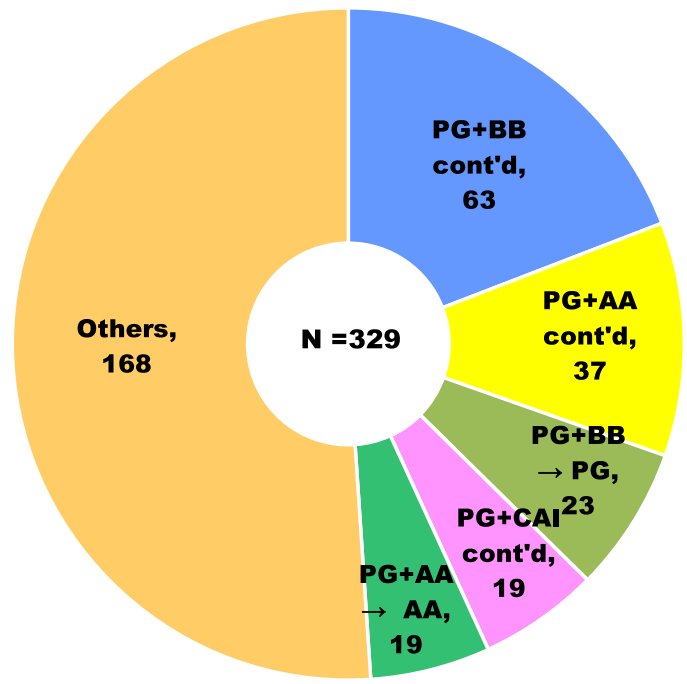

Fig. 3 Switching patterns from the fixed-combination (a) and unfixed-combination (b) eye drops during the 12-month post-index period. AA, a2agonist; BB, $\beta$-blocker; CAl, carbonic anhydrase inhibitor; cont'd, continued; PG, prostaglandin analog

comorbidities, were not associated with nonadherence. In multivariate analyses, treatment (adjusted OR: 0.388 [95\% CI: 0.259, 0.583], $P<0.0001$ ) and HbA1c (adjusted OR: 1.606 per $1 \%$ [95\% CI: $1.105,2.333], P=0.0130$ ) were also considered as significant risk factors.

Kaplan-Meier curves of persistence are presented in Fig. 4a. According to nonoverlapping 95\% CIs, more patients in the fixed-combination cohort than in the unfixed cohort continued their treatment after 2 months post-index, with a significant difference between the two cohorts (log-rank test, $P<0.0001)$. The persistence rates at 6 and 12 months post-index were approximately 67.6\% (95\% CI: 62.1, 72.5) and 47.6\% (95\% CI: 41.9, 53.0), respectively, in the fixed-combination cohort, and
$48.0 \%(95 \%$ CI: $42.5,53.3)$ and $24.9 \%$ (95\% CI: 20.4 , 29.7), respectively, in the unfixed-combination cohort.

Likewise, the persistence rate of the fixed-combination therapy with latanoprost and timolol was significantly higher than that of the unfixed-combination cohort (logrank test, $P=0.0001$ ) (Fig. 4b). Persistence rates at 6 and 12 months post-index were approximately $74.0 \%$ (95\% CI: $65.3,80.3$ ) and 54.5\% (95\% CI: 45.3, 62.8), respectively, in the latanoprost/timolol fixed-combination cohort and 46.2\% (95\% CI: 30.2, 60.7) and 25.6\% (95\% CI: $13.3,39.9)$, respectively, in the counterpart cohort.

Additionally, when compared between classes of the fixed-combination therapies, that is, PG/BB vs. CAI/BB, at 12 months post-index, the persistence rate of the PG/

Table 2 Adherence to fixed- and unfixed-combination therapies during the 12-month post-index period

\begin{tabular}{llll}
\hline & $\begin{array}{l}\text { All patients } \\
\boldsymbol{N}=\mathbf{6 3 8}\end{array}$ & $\begin{array}{l}\text { Fixed combination } \\
\boldsymbol{N = 3 0 9}\end{array}$ & $\begin{array}{l}\text { Unfixed combination } \\
\boldsymbol{N}=\mathbf{3 2 9}\end{array}$ \\
\hline PDC, mean \pm SD (\%) & $70.4 \pm 362$ & $79.1 \pm 32.1$ & $62.2 \pm 38.0$ \\
& $\mathrm{n}(\%)$ & $\mathrm{n}(\%)$ & $\mathrm{n}(\%)$ \\
$80+\%$ PDC & $375(58.8)$ & $215(69.6)$ & $160(48.6)$ \\
$<80 \%$ PDC & $263(41.2)$ & $94(30.4)$ & $169(51.4)$ \\
$60-79 \%$ PDC & $46(7.2)$ & $16(5.2)$ & $30(9.1)$ \\
$40-59 \%$ PDC & $43(6.7)$ & $24(7.8)$ & $19(5.8)$ \\
$20-39 \%$ PDC & $54(8.5)$ & $19(6.1)$ & $35(10.6)$ \\
$<20 \%$ PDC & $120(18.8)$ & $35(11.3)$ & $85(25.8)$ \\
\hline
\end{tabular}

PDC proportion of days covered

${ }^{a}, t$-test (fixed vs. unfixed); ${ }^{b}, x^{2}$ test (fixed vs. unfixed). Note: a $p$-value $<0.05 / 9(=0.00556)$ was considered statistically significant (by Bonferroni correction) 
Table 3 Adherence to fixed- and unfixed-combination therapies with latanoprost and timolol during the 12-month post-index period

\begin{tabular}{llll}
\hline & $\begin{array}{l}\text { All patients } \\
\boldsymbol{N}=\mathbf{1 6 2}\end{array}$ & $\begin{array}{l}\text { Fixed combination } \\
\boldsymbol{N}=\mathbf{1 2 3}\end{array}$ & $\begin{array}{l}\text { Unfixed combination } \\
\boldsymbol{N}=\mathbf{3 9}\end{array}$ \\
\hline PDC, mean \pm SD (\%) & $78.9 \pm 33.7$ & $82.9 \pm 31.1$ & $66.5 \pm 38.6$ \\
& $\mathrm{n}(\%)$ & $\mathrm{n}(\%)$ & $\mathrm{n}(\%)$ \\
$80+\%$ PDC & $114(70.4)$ & $93(75.6)$ & $21(53.8)$ \\
$<80 \%$ PDC & $48(29.6)$ & $30(24.4)$ & $18(46.2)$ \\
$60-79 \%$ PDC & $8(4.9)$ & $6(4.9)$ & $2(5.1)$ \\
$40-59 \%$ PDC & $9(5.6)$ & $5(4.1)$ & $4(10.3)$ \\
$20-39 \%$ PDC & $10(6.2)$ & $7(5.7)$ & $3(7.7)$ \\
$<20 \%$ PDC & $21(13.0)$ & $12(9.8)$ & $9(23.1)$ \\
\hline
\end{tabular}

$P D C$ proportion of days covered

${ }^{\mathrm{a}}, t$-test (fixed vs. unfixed); ${ }^{\mathrm{b}}, \mathrm{X}^{2}$ test (fixed vs. unfixed). Note: a p-value $<0.05 / 9(=0.00556)$ was considered statistically significant (by Bonferroni correction)

$\mathrm{BB}$ group was approximately $8 \%$ higher than that of the CAI/ BB group (49.4\% [95\% CI: 42.9, 55.5] vs. $41.2 \%$ [95\% CI: 29.5, 52.5]). However, it remained to be not statistically significant (log-rank test, $P=0.1454$ ) (Fig. 4c).

\section{Discussion}

The present study found that patients with fixedcombination therapy adhered to their therapies better than those with unfixed-combination therapy after switching from at least 12 months of monotherapy to a combination therapy with two drugs. Our findings are clinically important because no comparative study of adherence and persistence between fixed and unfixedcombination therapies has been reported in Japanese patients with glaucoma by using real-world data.

Most of the patients were prescribed with a combination of PG and $\mathrm{BB}$ in accordance with the guideline recommendation [9]. Overall, good adherence (PDC $\geq$ $80 \%)$ was noted in $58.8 \%$ of patients, lower than the results $(72.4 \%)$ of a nationwide survey using a

Table 4 Comparison of adherences to fixed-combination therapies during the 12-month post-index period

\begin{tabular}{llll}
\hline & $\begin{array}{l}P G / B \boldsymbol{B} \\
\boldsymbol{N}=\mathbf{2 4 1}\end{array}$ & $\begin{array}{l}\text { CAI/BB } \\
\boldsymbol{N}=\mathbf{6 8}\end{array}$ & \\
\hline PDC, mean \pm SD (\%) & $81.2 \pm 31.0$ & $71.6 \pm 34.9$ & $\mathrm{P}=0.0438^{\mathrm{a}}$ \\
& $\mathrm{n}(\%)$ & $\mathrm{n}(\%)$ & \\
$80+\%$ PDC & $176(73.0)$ & $39(57.4)$ & $\mathrm{P}=0.0131^{\mathrm{b}}$ \\
$<80 \%$ PDC & $65(27.0)$ & $29(42.6)$ & \\
$60-79 \%$ PDC & $12(5.0)$ & $4(5.9)$ & \\
$40-59 \%$ PDC & $15(6.2)$ & $9(13.2)$ & \\
$20-39 \%$ PDC & $13(5.4)$ & $6(8.8)$ & \\
$<20 \%$ PDC & $25(10.4)$ & $10(14.7)$ &
\end{tabular}

PDC proportion of days covered, $P G$ prostaglandin analogs, $B B$-blockers, $C A I$ carbonic anhydrase inhibitors

${ }^{a}$, $t$-test (PG/BB vs. CAl/BB); ${ }^{b}, x^{2}$ test (PG/BB vs. CAl/BB). Note: a $p$-value $<0.05$ $9(=0.00556)$ was considered statistically significant (by Bonferroni correction) questionnaire in Japan [16]. In the fixed-combination cohort, $47.6 \%$ of patients continued the two-drug combination drugs at 12 months post-index, and $69.6 \%$ showed good adherence during the 12 months. Patients receiving a fixed-combination also had a higher 12-month persistence rate. The persistence rate of latanoprost/timolol fixed-combination was as high as $54.5 \%$. Otherwise, most patients continued treatment using the same drops or the same class of drops, or switched to add-on therapy with the third drug (AA or CAI), suggesting that a fixed-combination was preferred. Although not significant, the PG/BB type had a slightly higher persistence rate than the CAI/BB type. Meanwhile, in the unfixedcombination cohort, only approximately $50 \%$ of the patients had good adherence. Furthermore, only $24.9 \%$ stayed on the unfixed two-drug combination therapy at 12 months post-index. Of note, the persistence rate of unfixed latanoprost plus timolol was as low as $25.6 \%$. Therefore, if eye drops had the same combination, the fixed-combination therapy would achieve high adherence and persistence.

The major reason for the high adherence of the fixed combination therapy may be because they are more convenient for patients. An interval of $5 \mathrm{~min}$ or more is required when two ophthalmic solutions are used in unfixed combination eye drops, whereas two types of eye drops can easily be administered using a single eye drop in fixed combination drugs. Moreover, the number of eye drops and applications in fixed combinations are very small. Furthermore, to reduce the physical and economic burden on patients, physicians should explain to patients that the use of the fixed-combination therapies is advantageous because it requires less frequent medication and decreased exposure to preservatives (decreased risk of developing ocular surface diseases) $[30,31]$ with similar efficacies $[15,32-34]$, or possibly superior in daily practice [35], compared with unfixed-combination therapies. 
Table 5 Risk factors for nonadherence (PDC < 80\%) to medications

\begin{tabular}{|c|c|c|c|}
\hline Variable & $\begin{array}{l}\text { Univariate } \\
P \text { Value }\end{array}$ & $\begin{array}{l}\text { Multivariate } \\
\text { P Value }\end{array}$ & $\begin{array}{l}\text { Odds ratio } \\
(95 \% \mathrm{Cl})\end{array}$ \\
\hline $\begin{array}{l}\text { Fixed vs. unfixed } \\
\text { combination therapies }\end{array}$ & $<0.0001$ & $<0.0001$ & $0.388(0.259,0.583)$ \\
\hline Sex & 0.4583 & & \\
\hline Age & 0.6787 & & \\
\hline Body weight & 0.9582 & & \\
\hline Height & 0.4747 & & \\
\hline Body mass index & 0.5763 & & \\
\hline Smoking habit & 0.5399 & & \\
\hline $\begin{array}{l}\text { Medication for other } \\
\text { disease }\end{array}$ & 0.9166 & & \\
\hline Antihypertensive drug & 0.6910 & & \\
\hline Fasting blood glucose & 0.4806 & & \\
\hline $\mathrm{HbA1c}$ & 0.0219 & 0.0130 & $1.606(1.105,2.333)$ \\
\hline Urine glucose & 0.2091 & & \\
\hline Urine protein & 0.3810 & & \\
\hline Systolic blood pressure & 0.3303 & & \\
\hline Diastolic blood pressure & 0.6046 & & \\
\hline Total cholesterol & 0.3382 & & \\
\hline Triglyceride & 0.7453 & & \\
\hline 47 prefectures & $>0.9999$ & & \\
\hline 8 regions & 0.7097 & & \\
\hline East vs. West Japan & 0.1569 & & \\
\hline City size & 0.4610 & & \\
\hline Hypertension & 0.5190 & & \\
\hline Cancer & 0.3087 & & \\
\hline Hyperlipidemia & 0.8102 & & \\
\hline Diabetes mellitus & 0.4790 & & \\
\hline Insomnia & 0.1181 & & \\
\hline Liver disorder & 0.9745 & & \\
\hline Asthma or COPD & 0.6839 & & \\
\hline Gastrointestinal ulcer & 0.7023 & & \\
\hline Atherosclerosis or PAOD & 0.8851 & & \\
\hline Anemia & 0.1098 & & \\
\hline Coronary artery disease & 0.4576 & & \\
\hline Heart failure & 0.1229 & & \\
\hline
\end{tabular}

Cl confidence interval, COPD chronic obstructive pulmonary disease, $P A O D$ peripheral arterial occlusive disease, $P D C$ proportion of days covered

In an overseas clinical study, patients can better adhered with fixed-combination therapies than with unfixed-combination therapies [15]. Considering that good adherence to therapies is critical for controlling glaucoma progression $[9,36,37]$, we believe that a fixed-combination therapy is an advantageous option for glaucoma treatment.
Given that the analyzed patients had received eye drop monotherapy for at least 1 year and continued to visit hospitals, they seemed to have been educated by doctors and have possibly understood the importance of continuing treatment with eye drops. However, many patients were nonadherent to the index therapy. In fact, an unfixed-combination therapy was consistently a risk factor for adherence. Furthermore, a high HbA1c level, but not diabetes mellitus, was another risk factor for nonadherence to the treatment. Considering the small sample size and numerous missing data, HbA1c is carefully concluded as a risk factor. However, diabetic patients with higher HbA1c levels are apt to be nonadherent to the therapy because a higher HbA1c level; i.e., poor glycemic control can be partly explained by poor adherence to antidiabetic medications and medical visits [38-41]. Type 2 diabetes mellitus, as well as glaucoma, is a chronic disease in which patients may have few symptoms despite having complex medication. If patients have complications, they need to take more pills at different times as per medicine. These patients may pay minimal attention to eye drops, leading to glaucoma progression. Therefore, glaucoma should be treated with continuous intervention in patients with diabetes mellitus, especially patients with poor glycemic control.

Moreover, other common risk factors were previously identified [12-14]. All of these risk factors need to be solved by education, communication with patients, and patient training in improving proficiency of selfadministration of eye drops [42].

Specific reasons on why physicians prescribed unfixed combinations for certain patients would be interesting to identify. Such reasons may include a risk of adverse events caused by the concentration of the fixedcombination, preservative formulations, and dosage adjustment of eye drops. If so, developing a new fixedcombination therapy would be worthwhile.

This study, however, has limitations. First, this study assumes that patients took eye drops for the number of days that they were prescribed, because the claims database does not track whether the patient actually administrated the eye drops as prescribed. However, we set a 30-day grace period so that the PDC did not underestimate adherence. Second, the study did not consider baseline PDC in patients that had being continuing monotherapy for 12 months prior to the index date, although baseline may or may not differ between the groups. Third, we used the MinaCare database to gather healthcare information covering nearly 2 million individuals, of which $90 \%$ were aged $20-59$ years who worked for a nationwide large company, of which, most individuals lived in Tokyo or large cities in East Japan, and their dependents in private corporate health insurance societies $[24,25]$. Therefore, regional and income biases 


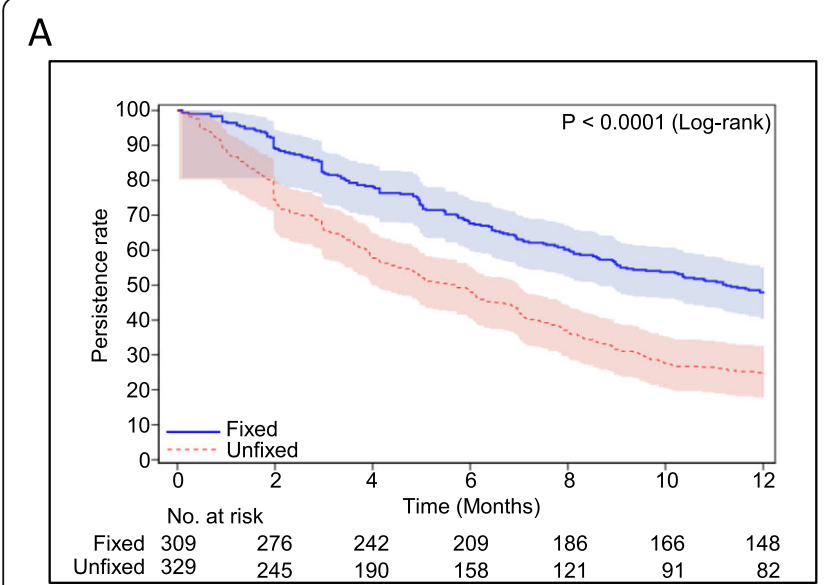

B

C
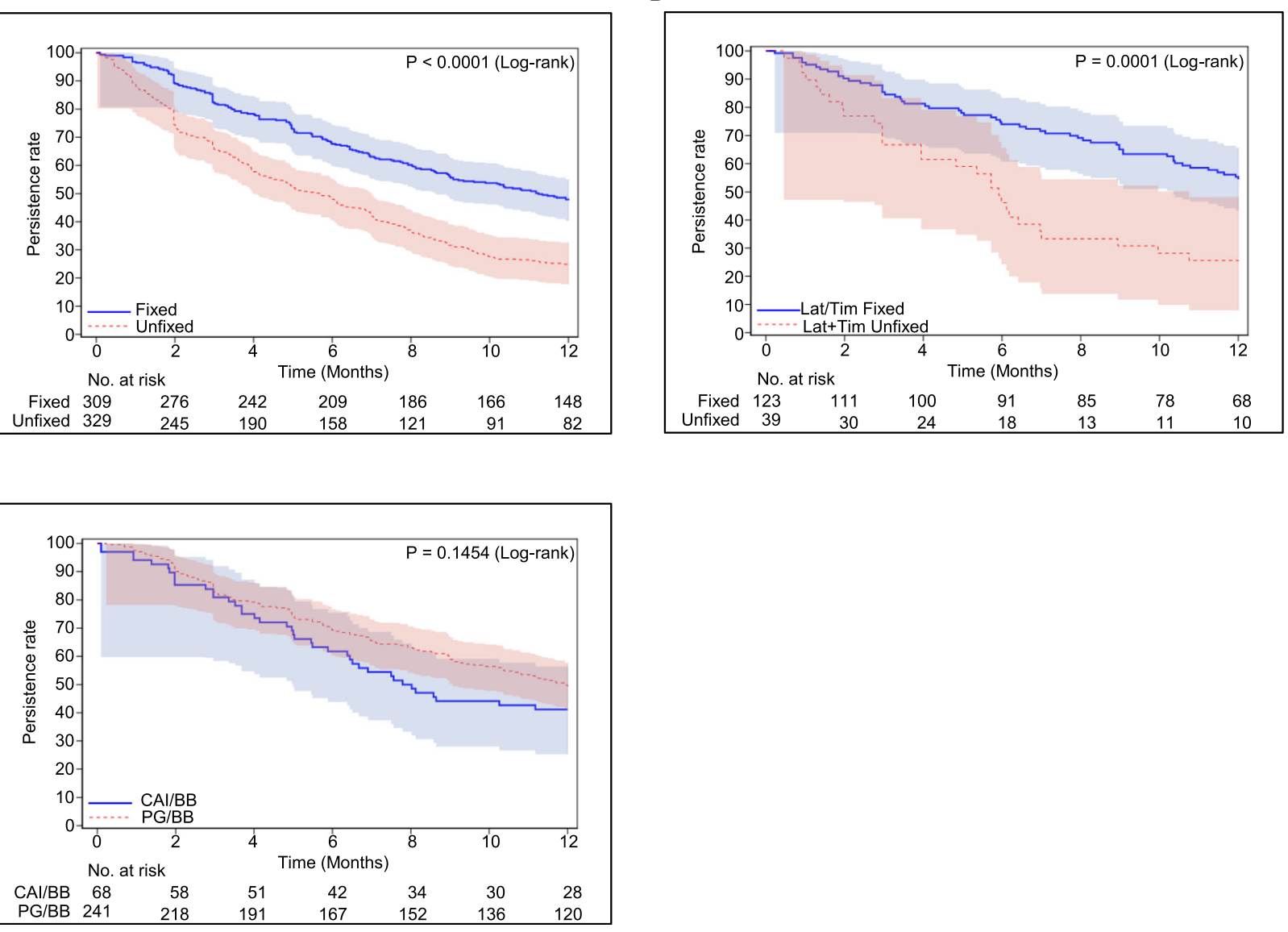

Fig. 4 Kaplan-Meier survival curves for the treatment persistence with fixed-vs. unfixed-combination therapies (a), fixed-vs. unfixed-combination therapies with Lat and Tim (b), and fixed-combination therapies with PG and BB vs. CAI and BB (c). Bars were Hall-Wellner bands. BB, $\beta$-blocker; CAl, carbonic anhydrase inhibitor; Lat, latanoprost; PG, prostaglandin analog; Tim, timolol

might have affected the results. Moreover, only few elderly patients were included in this study. However, this study is worth considering for treating glaucoma because young patients are more likely to have glaucoma progression during their long life-spans. Fourth, the patients between the two cohorts possessed an uncontrolled nature, which includes the numerous drug types used as monotherapy during the pre-index period and the severity of glaucoma. Although background information and baseline characteristics were limited, they were similar between the two cohorts. Finally, the present analyses were built according to the assumption that all of the claimed drugs were used by the patients. To address these limitations, we need to conduct further studies using the real-world data combined with clinical data.

\section{Conclusions}

The present results using the real-world data showed that city patients who received fixed-combination therapies exhibited better adherence to medications compared with those who received unfixed-combination therapies. A high HbA1c level was one risk factor for nonadherence. Therefore, a fixed-combination therapy would better serve as a glaucoma therapy, considering that adherence to the therapy is a key for effectively preventing glaucoma progression.

\section{Abbreviations}

AA: a2-agonist; BB: $\beta$-blocker; CAl: Carbonic anhydrase inhibitor; $\mathrm{Cl}$ : Confidence interval; HbA1c: Hemoglobin A1c; IOP: Intraocular pressure; MIGS: Minimally invasive glaucoma surgery; NS: Not significant; OR: Odds ratio; PDC: Proportion of days covered; PG: Prostaglandin analog;

SD: Standard deviation; SLT: Selective laser trabeculoplasty

\section{Acknowledgments}

This study was financially supported by Pfizer Japan Inc. The authors are grateful to Yuji Yamamoto, M.D., M.B.A., MinaCare Co., Ltd. for supplying data for this study. We also thank medical writer Takahiko Murata, Ph.D., WysiWyg Co., Ltd. for his assistance in the preparation of this manuscript.

\section{Authors' contributions}

CS, NM and TN were involved in the conceptual development and study design. NM performed the statistical analyses. All authors participated in the interpretation of the data and in drafting and/or revising the manuscript critically for developing important intellectual content. All authors gave their final approval to the manuscript to be submitted. 


\section{Funding}

This study was financially supported by Pfizer Japan Inc.

\section{Availability of data and materials}

The data that support the findings of this study are available from MinaCare but restrictions apply to the availability of these data, which were used under license for the current study, Therefore, the data are not publicly available. The data are however available from the authors upon reasonable request and with the permission of MinaCare.

\section{Ethics approval and consent to participate}

This study used subject-level electronic health related databases that protected the identity of the individuals. MinaCare is allowed to use such anonymized data under the data transfer contract with its client health insurers. Although this study is outside the scope of the guidelines because the data is protected by anonymization, we referred to the "Ethical Guidelines for Epidemiological Research" laid down by the Japanese government [23]

\section{Consent for publication}

Not applicable.

\section{Competing interests}

Chikako Shirai is a full-time employee of Pfizer Japan Inc. Nobushige Matsuoka is a full-time employee of Pfizer R\&D Japan G.K. Toru Nakazawa is a Professor of Tohoku University Graduate School of Medicine and has no conflicts of interest associated with this manuscript.

\section{Author details}

'Medical Affairs, Pfizer Japan Inc., 3-22-7 Yoyogi, Shibuya-ku, Tokyo 151-8589, Japan. ${ }^{2}$ Biometrics \& Data Management, Pfizer R\&D Japan G.K, 3-22-7 Yoyogi, Shibuya-ku, Tokyo 151-8589, Japan. ${ }^{3}$ Department of Ophthalmology, Tohoku University Graduate School of Medicine, 1-1 Seiryo-machi, Aoba-ku, Sendai, Miyagi 980-8574, Japan.

Received: 22 July 2020 Accepted: 12 January 2021

Published online: 21 January 2021

\section{References}

1. Morizane Y, Morimoto N, Fujiwara A, et al. Incidence and causes of visual impairment in Japan: the first nation-wide complete enumeration survey of newly certified visually impaired individuals. Jpn J Ophthalmol. 2019;63:2633.

2. Coleman AL, Kodjebacheva G. Risk factors for glaucoma needing more attention. Open Ophthalmol J. 2009;3:38-42.

3. Cohen LP, Pasquale LR. Clinical characteristics and current treatment of glaucoma. Cold Spring Harb Perspect Med. 2014;4:a017236.

4. Kastner A, King AJ. Advanced glaucoma at diagnosis: current perspectives. Eye (Lond). 2020;34:116-28.

5. Lee JWY, Chan PP, Zhang $X$, Chen LJ, Jonas JB. Latest developments in normal-pressure glaucoma: diagnosis, epidemiology, genetics, etiology, causes and mechanisms to management. Asia Pac J Ophthalmol (Phila). 2019;8:457-68

6. Kass MA, Heuer DK, Higginbotham EJ, et al. The ocular hypertension treatment study: a randomized trial determines that topical ocular hypotensive medication delays or prevents the onset of primary open-angle glaucoma. Arch Ophthalmol. 2002;120:701-13 discussion 829-830.

7. Leske MC, Heijl A, Hussein M, et al. Factors for glaucoma progression and the effect of treatment: the early manifest glaucoma trial. Arch Ophthalmol. 2003;121:48-56.

8. Gazzard G, Konstantakopoulou E, Garway-Heath D, et al. Selective laser trabeculoplasty versus eye drops for first-line treatment of ocular hypertension and glaucoma (LiGHT): a multicentre randomised controlled trial. Lancet. 2019:393(10180):1505-16.

9. The Japan Glaucoma Society Guidelines for Glaucoma (4th Edition) (in Japanese). http://www.nichigan.or.jp/member/guideline/glaucoma4.pdf. Accessed 22 Jul 2020.

10. Wolfram C, Stahlberg E, Pfeiffer N. Patient-reported nonadherence with glaucoma therapy. J Ocul Pharmacol Ther. 2019;35:223-8.

11. Meier-Gibbons F, Berlin MS, Töteberg-Harms M. Influence of new treatment modalities on adherence in glaucoma. Curr Opin Ophthalmol. 2019;30:104-9.
12. Tsai JC, McClure CA, Ramos SE, Schlundt DG, Pichert JW. Compliance barriers in glaucoma: a systematic classification. J Glaucoma. 2003;12:393-8.

13. Newman-Casey PA, Robin AL, Blachley $T$, et al. The most common barriers to glaucoma medication adherence: a cross-sectional survey. Ophthalmology. 2015;122:1308-16.

14. Robin AL, Muir KW. Medication adherence in patients with ocular hypertension or glaucoma. Expert Rev Ophthalmol. 2019;14:199-210.

15. Barnebey HS, Robin AL. Adherence to fixed-combination versus unfixed travoprost 0.004\%/timolol 0.5\% for glaucoma or ocular hypertension: a randomized trial. Am J Ophthalmol. 2017:176:61-9.

16. Tsumura T, Kashiwagi K, Suzuki Y, et al. A nationwide survey of factors influencing adherence to ocular hypotensive eyedrops in Japan. Int Ophthalmol. 2019:39:375-83.

17. Nordstrom BL, Friedman DS, Mozaffari E, Quigley HA, Walker AM. Persistence and adherence with topical glaucoma therapy. Am J Ophthalmol. 2005;140:598-606

18. Friedman DS, Quigley HA, Gelb L, et al. Using pharmacy claims data to study adherence to glaucoma medications: methodology and findings of the glaucoma adherence and persistency study (GAPS). Invest Ophthalmol Vis Sci. 2007;48:5052-7.

19. Yeaw J, Benner JS, Walt JG, Sian S, Smith DB. Comparing adherence and persistence across 6 chronic medication classes. J Manag Care Pharm. 2009; 15:728-40.

20. Campbell JH, Schwartz GF, LaBounty B, Kowalski JW, Patel VD. Patient adherence and persistence with topical ocular hypotensive therapy in realworld practice: a comparison of bimatoprost $0.01 \%$ and travoprost Z $0.004 \%$ ophthalmic solutions. Clin Ophthalmol. 2014;8:927-35.

21. Tse AP, Shah M, Jamal N, Shaikh A, et al. Eye (Lond). 2016;30:1118-22.

22. Sheer R, Bunniran S, Uribe $C$, et al. Predictors of nonadherence to topical intraocular pressure reduction medications among medicare members: a claims-based retrospective cohort study. J Manag Care Spec Pharm. 2016;22: 808-817a.

23. The Ministry of Education, Culture, Sports, Science and Technology of Japan, the Ministry of Health, Labour and Welfare of Japan. Ethical guidelines for medical and health research involving human subjects: https://www.mhlw.go.jp/file/06-Seisakujouhou-10600000Daijinkanboukouseikagakuka/0000080278.pdf. Accessed 22 Jul 2020

24. Shima D, li $Y$, Yamamoto $Y$, et al. A retrospective, cross-sectional study of real-world values of cardiovascular risk factors using a healthcare database in Japan. BMC Cardiovasc Disord. 2014;14:120.

25. Yuasa A, Murata T, Imai K, Yamamoto Y, Fujimoto Y. Treatment procedures and associated medical costs of methicillin-resistant Staphylococcus aureus infection in Japan: a retrospective analysis using a database of Japanese employment-based health insurance. SAGE Open Med. 2019;7: 2050312119871181.

26. Pharmacoepidemiology \& Database Taskforce, Japanese Society for Pharmacoepidemiology. Databases available for pharmacoepidemiology researches in Japan (information obtained from suvey answers as of August 2019): http://www.jspe.jp/mt-static/FileUpload/files/JSPE_DB_TF_E.pdf. Last accessed on May 13, 2020.

27. The Ministry of Foreign Affairs of Japan (MOFA). Regions of Japan Kid Web Japan: https://web-japan.org/kidsweb/explore/regions/index.html. Accessed 22 Jul 2020.

28. Asahi Net Home Page.: https://asahi-net.jp/en/service/ftth/withflets/index_ area.html. Accessed 22 Jul 2020.

29. Council of Local Authorities for International Relations (CLAIR). 2012 Local government in Japan.: http://www.clair.or.jp/j/forum/pub/pdf/jichi12_en.pdf. Accessed 22 Jul 2020.

30. Rosin LM, Bell NP. Preservative toxicity in glaucoma medication: clinical evaluation of benzalkonium chloride-free $0.5 \%$ timolol eye drops. Clin Ophthalmol. 2013;7:2131-5.

31. Asiedu K, Abu SL. The impact of topical intraocular pressure lowering medications on the ocular surface of glaucoma patients: a review. J Curr Ophthalmol. 2019:31:8-15.

32. Zhao JL, Ge J, Li XX, et al. Comparative efficacy and safety of the fixed versus unfixed combination of latanoprost and timolol in Chinese patients with open-angle glaucoma or ocular hypertension. BMC Ophthalmol. 2011;11:23.

33. Bhagat P, Sodimalla K, Paul C, et al. Efficacy and safety of benzalkonium chloride-free fixed-dose combination of latanoprost and timolol in patients with open-angle glaucoma or ocular hypertension. Clin Ophthalmol. 2014;8: $1241-52$. 
34. Nagayama M, Nakajima T, Ono J. Safety and efficacy of a fixed versus unfixed brinzolamide/timolol combination in Japanese patients with openangle glaucoma or ocular hypertension. Clin Ophthalmol. 2014;8:219-28.

35. Lanzl I, Raber T. Efficacy and tolerability of the fixed combination of brinzolamide 1\% and timolol 0.5\% in daily practice. Clin Ophthalmol. 2011;5: 291-8.

36. Broadway DC, Cate H. Pharmacotherapy and adherence issues in treating elderly patients with glaucoma. Drugs Aging. 2015;32:569-81.

37. Atey TM, Shibeshi W, Giorgis AT, Asgedom SW. The impact of adherence and instillation proficiency of topical glaucoma medications on intraocular pressure. J Ophthalmol. 2017;2017:1683430.

38. Nagrebetsky A, Griffin S, Kinmonth AL, et al. Predictors of suboptimal glycaemic control in type 2 diabetes patients: the role of medication adherence and body mass index in the relationship between glycaemia and age. Diabetes Res Clin Pract. 2012;96:119-28.

39. Feldman BS, Cohen-Stavi CJ, Leibowitz $M$, et al. Defining the role of medication adherence in poor glycemic control among a general adult population with diabetes. PLoS One. 2014;9:e108145.

40. Lin LK, Sun Y, Heng BH, Chew DEK, Chong PN. Medication adherence and glycemic control among newly diagnosed diabetes patients. BMJ Open Diabetes Res Care. 2017;5:e000429.

41. García Díaz E, Ramírez Medina D, García López A, Morera Porras ÓM Determinants of adherence to hypoglycemic agents and medical visits in patients with type 2 diabetes mellitus. Endocrinol Diabetes Nutr. 2017;64: 531-8.

42. Feng $A, O^{\prime}$ Neill J, Holt $M$, et al. Success of patient training in improving proficiency of eyedrop administration among various ophthalmic patient populations. Clin Ophthalmol. 2016;10:1505-11.

\section{Publisher's Note}

Springer Nature remains neutral with regard to jurisdictional claims in published maps and institutional affiliations.

Ready to submit your research? Choose BMC and benefit from:

- fast, convenient online submission

- thorough peer review by experienced researchers in your field

- rapid publication on acceptance

- support for research data, including large and complex data types

- gold Open Access which fosters wider collaboration and increased citations

- maximum visibility for your research: over $100 \mathrm{M}$ website views per year

At $\mathrm{BMC}$, research is always in progress.

Learn more biomedcentral.com/submissions 